ZOOLOGIA 30 (6): 615-622, December, 2013

http://dx.doi.org/10.1590/S1984-46702013005000010

\title{
Effect of the insecticide Lambda-cyhalothrin on rice spider populations in southern Brazil
}

\section{Everton N. L. Rodrigues ${ }^{1,4}$, Milton de S. Mendonça Jr², Leila L. Fritz', Elvis A. Heinrichs ${ }^{3} \&$ Lídia Fiuza $^{1}$}

\author{
1 Programa de Pós-Graduação em Biologia, Universidade do Vale do Rio dos Sinos. Avenida Unisinos 950, Caixa Postal 275, \\ 93022-000 São Leopoldo, RS, Brazil. \\ ${ }^{2}$ Departamento de Ecologia, Instituto de Biociências, Universidade Federal do Rio Grande do Sul. Avenida Bento Gonçalves \\ 9500, Bloco IV, Prédio 43422, 91501-970 Porto Alegre, RS, Brazil. \\ ${ }^{3}$ Department of Entomology, University of Nebraska. Entomology Hall, 68583-0816 Lincoln, Nebraska, USA. \\ ${ }^{4}$ Corresponding author. E-mail: enlrodrigues@yahoo.com.br
}

\begin{abstract}
The adverse effect that insecticides have on spider populations is of major concern since these predators are a component in the biological control of rice insect pest populations. This study was designed to determine the effect of the pyrethroid insecticide, Lambda-cyhalothrin, on spider populations in rice fields. Treatments consisted of plots treated once with the insecticide and untreated plots (control). Spiders were sampled four times per crop year over a two year period in each of three sites in the state of Rio Grande dol Sul, Brazil. Treatments were replicated four times. Sweep net sampling was conducted to sample the araneofauna. Overall 1,961 spiders were collected, with a predominance of juveniles over adults. Between treatments, there were significantly larger numbers of spiders and species richness in areas without insecticide. There were also significant differences among areas (sites) and among days after the insecticide application. Of the 12 recorded families, Araneidae and Tetragnathidae dominated, and were both strongly affected by insecticide application, decreasing more than 50\% in those locations. Overall, 37 species were recorded (insecticide: 29; without: 26), eleven species were exclusive for rice without insecticide and eight for rice with insecticide. Alpaida veniliae (Keyserling, 1865) $(\mathrm{n}=236)$ and Tetragnatha aff. jaculator $(108)$ were the most abundant in both treatments, but with large decreases in abundance in rice with insecticide. Among guilds, the predominance was for orb weavers $(67.3 \%)$ in all locations, but with much lower values for those spiders in rice with insecticide application. This study illustrates that the spider fauna in rice fields are adversely affected by the application of the insecticide Lambda-cyhalothrin.
\end{abstract}

KEY WORDS. Rice culture; spider abundance; spider composition; species richness; Lambda-cyhalothrin.

Insecticides are commonly used to control rice insect pests, however, these insecticides also affect beneficial organisms (Croft 1990, Desneux et al. 2007, PerÁr 2012), including spiders. These predaceous species consume large numbers of prey while being harmless to the plants (Rodrigues et al. 2009). Thus, a balance in the number of pests can be reached, equivalent to a natural control process, with their own numbers restricted by intrinsic ecological processes such as territoriality and cannibalism (LEE \& KIM 2001). Agriculture without insecticides, such as organic farming, has been considered to not only increase this ecosystem service of natural pest control but also preserve the native biodiversity in agroecosystem landscapes (PONCE et al. 2011).

A few papers exist on the spider fauna associated with rice culture in southern Brazil (CoRseuIl et al. 1994, RoDrigues et al. 2009, Fritz et al. 2011); however, no one evaluated the effect of insecticide on the spider assemblage. Insecticides have been reported to influence the predator fauna in rice fields, usually reducing their population (LeE et al. 1993, KumAR \& VelusAmy 1996, TANaKa et al. 2000, BandaradeniYa \& Edirisinghe 2001, Bora et al. 2004, KatTi et al. 2001, Vardhani \& Rao 2002, Fritz et al. 2011, PекÁr 2012). In addition to insecticides, herbicides can also lower spider abundance (HaUghton et al. 1999, BandaradeniYa \& Edirisinghe 2001, Haughton et al. 2001, Bell et al. 2002).

Insect species causing damage to the rice culture have been recorded as prey for spiders - e.g., Conocephalus sp. and Hortensia similis (Walker 1851) preyed on by Alpaida veniliae (Keyserling, 1865) (SAAVEDRA et al. 2007) -, with the latter indicated as an efficient predator (SigsgaARd 2000, Murata \& TANAKA 2004, SAAVEDRA et al. 2007, PeKÁR 2012). Spiders are thus known as biological control agents for phytophagous insects (Young \& Lockley 1985, Riechert \& Lockley 1984, SaAvedra et al. 2007, 
Fritz et al. 2011, TAHIR et al. 2009) with some species being able to reduce the total pest population by $22 \%$ per day (TAHIR et al. 2009). Hunter and weaver spider species have been recorded in all development stages of the rice culture (ANBALAGAN \& Narayanasamy 1999, Bandaradeniya \& Edirisinghe 2001, Didonet et al. 2001, Rodrigues et al. 2009) and thus serve as excellent subjects for evaluating the effect of chemical substances on agroecosystems. The excessive use of insecticides, to control insect pest populations, results in damage to the agroecosystem by promoting a proliferation of pests through the decrease in natural enemy populations (Fritz et al. 2011). This again highlights the importance of maintaining biological diversity and predator-prey interactions as intact as possible in these artificial systems (Perfecto et al. 1997, Fritz et al. 2011).

Spiders are usually divided into feeding strategy guilds; some species depend on the use of webs for capturing prey (weaving spiders) while some hunt prey (hunters). A number of detailed classification schemes have been proposed, but the lack of knowledge on some species and genera of spiders, for example in the Neotropics, are problematic for these classifications (Rodrigues et al. 2009, DiAs et al. 2010). Uetz et al. (1999) constructed an hierarchical scheme from which from two to 32 spider guilds could be derived. This functional view of spiders complements the taxonomic interpretation of diversity (richness, usually for species) and may explain the responses of this fauna to disturbances such as insecticides.

Spiders are found in almost all known ecosystems, including agricultural ecosystems such as rice. However, field studies elucidating the influence of insecticides on spider populations in Brazilian rice fields are scarce. The aim of this paper is to test the hypothesis that spider diversity in the rice culture is affected by the use of insecticides, in terms of abundance, species richness, species composition and feeding guild.

\section{MATERIAL AND METHODS}

Sampling was done in three irrigated rice producing in Rio Grande do Sul (RS), southern Brazil: Capivari do Sul (hence-

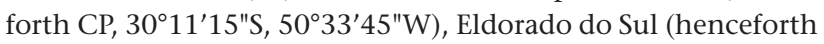
ES, $30^{\circ} 05^{\prime} 40^{\prime \prime} \mathrm{S}, 51^{\circ} 33^{\prime} 45^{\prime \prime} \mathrm{W}$ ) and Cachoeira do Sul (henceforth $\mathrm{CC}, 30^{\circ} 03^{\prime} 45^{\prime \prime} \mathrm{S}, 52^{\circ} 55^{\prime} 15^{\prime \prime} \mathrm{W}$ ). These sites (areas) correspond to three different physiographic regions of RS: External Coastal Plain, Internal Coastal Plain and Central Depression, respectively (Fritz et al. 2011). Each study plot is composed of two smaller subplots of $1,200 \mathrm{~m}^{2}$, subdivided into four $300 \mathrm{~m}^{2}$ sections. One of the subplots received one application of the pyrethroid insecticide, Lambda-cyhalothrin 50 CS $\left(150 \mathrm{~mL} / \mathrm{ha}^{-1}\right)$, while the other remained unsprayed (control). Lambda-cyhalothrin is an insecticide widely used in Brazil. The insecticide was applied with a $\mathrm{CO}_{2}$ propelled backpack sprayer, regulated to $35 \mathrm{lb} / \mathrm{in}^{2}$, equipped with four cone-like beaks, equidistant $0.5 \mathrm{~m}$ between them. Treatments were separated by a high mud dike (at least 2 $\mathrm{m}$ high) and a $5 \mathrm{~m}$ distance between plots to avoid spray con- tamination of unsprayed plots and spider dispersal among plots. Spider sampling occurred in fortnightly periods during the rice culture development, for two agricultural years (growing seasons: $2007 / 2008$ and 2008/2009). The first sample was taken two days after insecticide (DAI) application. In 2007/2008, samples were taken 2, 16, 31 and 44 DAI (9 and 23 January, 7 and 20 February in CC and ES, and 10 and 24 January, 8 and 21 February in CP). In 2008/2009 samples occurred 2, 16/17, 30/32 and 44/45 DAI (14 and 28 January, 13 and 26 February in CC and ES, 14 and 29 January, 11 and 25 February in CP). Spiders were sampled with a sweep net $(40 \times 36 \mathrm{~cm})$, with 50 swinging movements over the vegetation for each of four transects per treatment; transects are used as sampling units.

All spiders were separated to families and adults and identified to the species level when possible or to morphospecies level otherwise. Identification, cataloguing (MCN 43861-45991) and museum curation were conducted at the Laboratório de Aracnologia of the Museu de Ciências Naturais at the Fundação Zoobotânica do Rio Grande do Sul, Porto Alegre, Brazil (R. Ott, curator).

Statistical differences among areas (sites) (municipalities: CC, ES and CP), treatments (with insecticide and control), and times of sampling (days after insecticide application) were tested against spider diversity variables. Such variables were checked for normality previous to testing, with no transformations needed. To test the above factors for abundance and species richness simultaneously a multivariate general linear model (GLM) was implemented in PASW 18.0 (SPSS ${ }^{\circledR}$ ), with ANOVAs as tests for between-subject effects for each variable; Pillai's Trace was used. Species richness was adjusted with data from families, i.e. the number of species in a sample is at least the number of families (obtained from juveniles) in that sample. Area, treatment and times of sampling were included as fixed factors; year was included as a block measure. To test for statistical differences in species composition in respect to the three factors listed above, three one-way ANOSIM (analysis of similarity) with Bonferroni correction for repeated testing (CLARKE \& WARWICK 1994) were used. Family spider composition was tested with data including all individuals, (juveniles as well), and thus was also tested with ANOSIM, (details as above) for differences between treatments and areas. These analyses were carried out in PASt (Paleontological Statistics 1.97, Hammer \& Harper 2009).

To test whether different treatments influenced spider feeding guilds, a multivariate general linear model (GLM) similar to that used for abundance and richness (above) was implemented in PASW 18.0 (SPSS $\left.{ }^{\circledR}\right)$, with number of individual spiders in each guild a variable, including young spiders. Guild classification followed Uetz et al. (1999) and Rodrigues et al. (2009): a) web builders in two guilds: 1) orbicular orb weavers, ORB (bidimensional webs); 2) sheet web builders, SWB (tridimensional webs); b) hunters (spiders hunting prey without using webs) in two other guilds: 1) cursorial hunters, CUR (search and hunt prey actively), and 2) ambushers, AMB (sit-and-wait strategies). 


\section{RESULTS}

\section{Abundance and species richness}

Overall 1,961 spiders were collected, with most being juveniles ( $\mathrm{n}=1,387 ; 70.7 \%$ of the total).

Among adults, females dominated (55.1\%). Of the adults, 37 species or morphospecies could be identified (Table I). The MANOVA revealed significant differences in diversity (abundance and richness) among all three factors (Table II): treatments, DAI and areas. There were significant interactions between area and treatment for richness. In all cases, tests of between-subjects effects revealed both spider abundance and richness to respond in the same way to the factors, i.e. they were either both significant or non-significant, except for area and treatment interaction, for which there was a significant effect on richness but not on abundance. The insecticide effect was always toward less spiders and less species of spiders but the reduction in spider numbers varies depending on the area (Figs 1 and 2). In Figure 1 spider abundance is also clearly distinct among areas, with $\mathrm{CP}$ having lower numbers; richness also differs among areas (Fig. 2). This strong difference among areas actually rendered all relationships involving area as strongly significant. Insecticide effect after application takes some time to appear, being maximal after 14/15 days, and decays rather slowly, with samples taken $44 / 45$ days after treatment showing recovery (Figs 3 and 4), less marked for richness than for abundance. But, surprisingly, control areas also show reduction in abundance and richness.
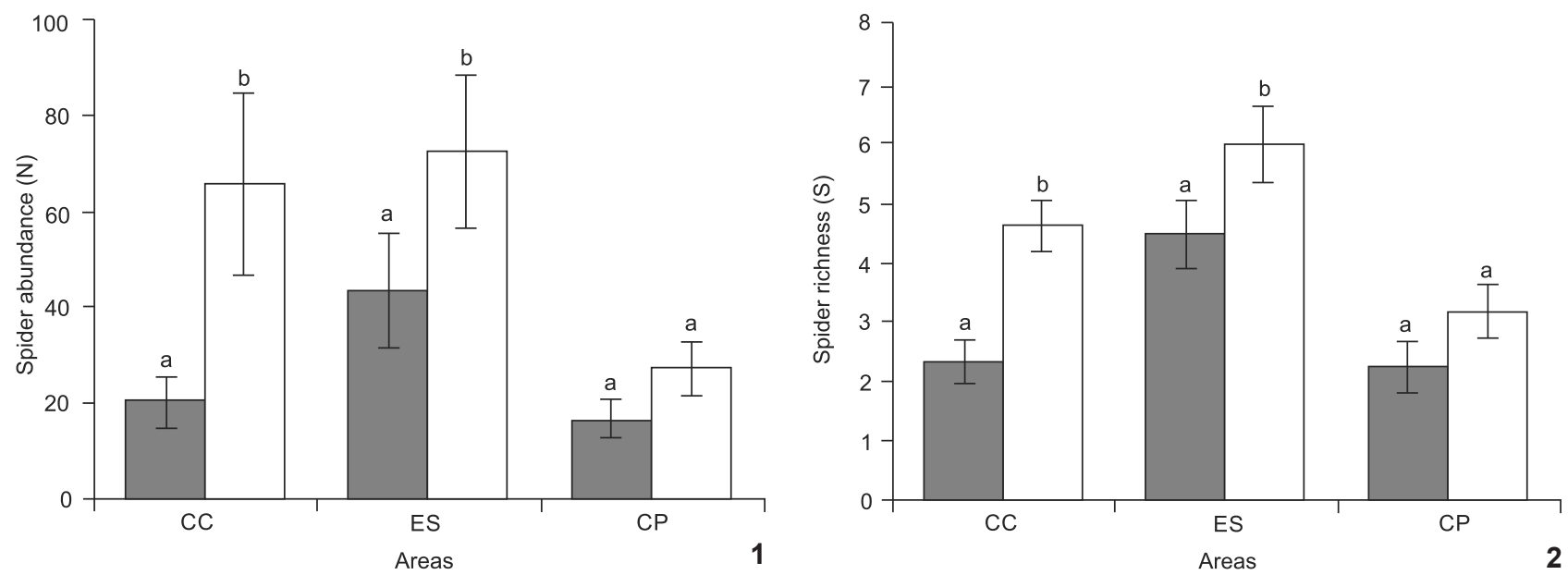

Figures 1-2. Average ( $\pm \mathrm{SE}$ ) spider diversity variables with and without insecticide application in rice fields at Capivari do Sul (CP), Eldorado do Sul (ES) and Cachoeira do Sul (CC), Rio Grande do Sul, Brazil. (1) Spider (juvenile and adults) abundance; (2) spider (adults) species richness. Letters indicate significant differences, $p<0.05$. ( $\square$ ) Control. ( $\square$ ) insecticide.
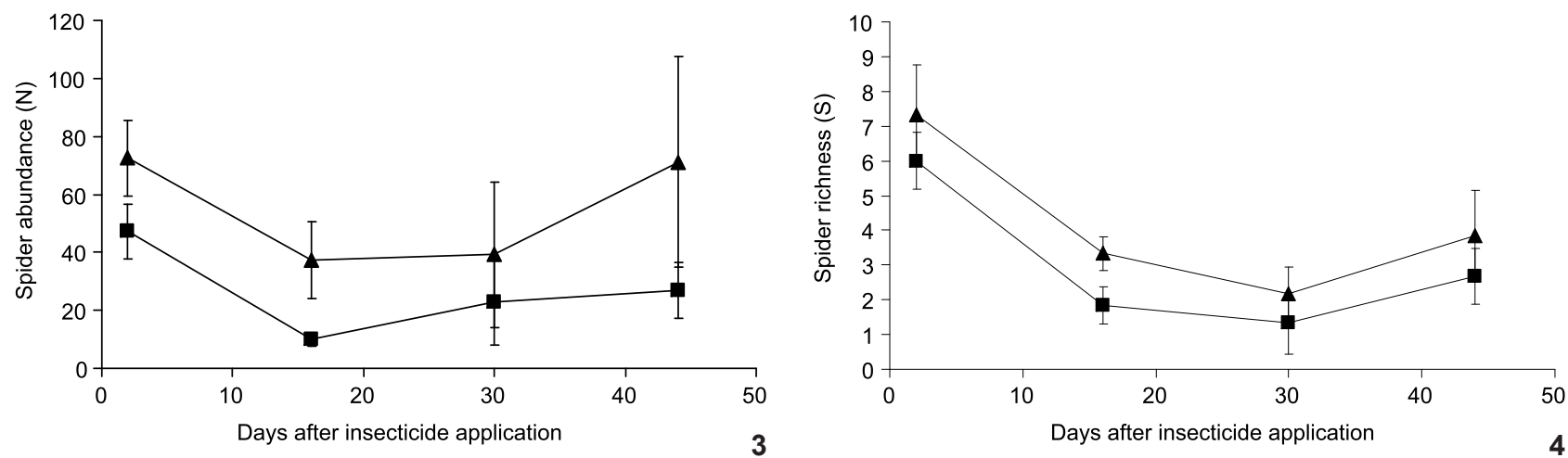

Figures 3-4. Average ( \pm SE) spider diversity variables in time (days) after insecticide application, in rice fields at Capivari do Sul, Eldorado do Sul and Cachoeira do Sul, Rio Grande do Sul, Brazil. (3) Spider (juvenile and adults) abundance; (4) spider (adults) species richness.

(A) Control, (ם) insecticide. 
Table I. Number of adult spiders from sweep net sampling in plots treated with insecticide and untreated in three rice areas of Rio Grande do Sul, Brazil.

\begin{tabular}{|c|c|c|c|c|c|c|c|}
\hline \multirow{3}{*}{ Family/Species } & \multicolumn{6}{|c|}{ Area/Treatment } & \multirow{3}{*}{ Total } \\
\hline & \multicolumn{2}{|c|}{ Cachoeira } & \multicolumn{2}{|c|}{ Eldorado } & \multicolumn{2}{|c|}{ Capivari } & \\
\hline & Insecticide & Control & Insecticide & Control & Insecticide & Control & \\
\hline \multicolumn{8}{|l|}{ Anyphaenidae } \\
\hline Acanthoceto acupictus (Nicolet, 1849) & & & 1 & 3 & 1 & 3 & 8 \\
\hline Arachosia bergi (Simon, 1880) & & 1 & & 1 & 1 & & 3 \\
\hline Arachosia honesta Keyserling, 1891 & & & & 1 & & 1 & 2 \\
\hline Arachosia sp. & 6 & 4 & 2 & 3 & 2 & 2 & 19 \\
\hline Sanogasta maculatipes (Keyserling, 1878) & 1 & 2 & 1 & 2 & & 6 & 12 \\
\hline \multicolumn{8}{|l|}{ Araneidae } \\
\hline Alpaida veniliae (Keyserling, 1865) & 6 & 46 & 37 & 131 & 3 & 13 & 236 \\
\hline Argiope argentata (Fabricius, 1775) & & 1 & & 1 & & & 2 \\
\hline Kaira sexta (Chamberlin, 1916) & & & 1 & 2 & & & 3 \\
\hline Metepeira gressa (Keyserling, 1892) & & & & & 2 & & 2 \\
\hline Larinia bivittata Keyserling, 1885 & & & & & & 3 & 3 \\
\hline Larinia tucuman Harrod, Levi \& Leibensperger, 1991 & & & & & & 2 & 2 \\
\hline \multicolumn{8}{|l|}{ Linyphiidae } \\
\hline Laminacauda montevidensis (Keyserling, 1878) & & & & & 1 & & 1 \\
\hline Lepthyphantes sp. & & 1 & & & & & 1 \\
\hline Lygarina sp. & & & 1 & & & & 1 \\
\hline Mermessus aff. dentiger & & & 1 & & & & 1 \\
\hline Mermessus sp. & 9 & 2 & 2 & & 5 & 2 & 20 \\
\hline Notiohyphantes excelsus (Keyserling, 1886) & & & & 2 & 1 & & 3 \\
\hline Erigone sp. & 3 & 1 & & 2 & & 3 & 9 \\
\hline Sphecozone ignigena (Keyserling, 1886) & 2 & & 6 & 2 & 3 & & 13 \\
\hline Sphecozone modesta (Nicolet, 1849) & & & & & & 1 & 1 \\
\hline Triplogyna sp. & & & 3 & & 1 & & 4 \\
\hline \multicolumn{8}{|l|}{ Lycosidae } \\
\hline Lycosidae indet.1 & 1 & 1 & & & & & 2 \\
\hline Lycosidae indet. 2 & 2 & & 2 & & & & 4 \\
\hline \multicolumn{8}{|l|}{ Miturgidae } \\
\hline Cheiracanthium inclusum (Hentz, 1847) & & 1 & & & & & 1 \\
\hline \multicolumn{8}{|l|}{ Oxyopidae } \\
\hline Oxyopes salticus Hentz, 1845 & 6 & 8 & 8 & 1 & 1 & & 24 \\
\hline \multicolumn{8}{|l|}{ Salticidae } \\
\hline Ashtabula sp. & & 1 & & & 1 & & 2 \\
\hline Sassacus sp. 1 & & & & 2 & & 1 & 3 \\
\hline Sassacus sp. 2 & 1 & & & & & & 1 \\
\hline Unidentati indet. & & & & 1 & & & 1 \\
\hline \multicolumn{8}{|l|}{ Tetragnathidae } \\
\hline Glenognatha lacteovittata (Mello-Leitão, 1944) & 1 & & 2 & & & & 3 \\
\hline Tetragnatha aff. jaculator & 4 & 10 & 16 & 67 & 3 & 8 & 108 \\
\hline Tetragnatha nitens (Audouin, 1826) & 2 & 55 & & 1 & & 3 & 61 \\
\hline Tetragnatha aff. pallescens & & 1 & 1 & 2 & & 1 & 5 \\
\hline \multicolumn{8}{|l|}{ Theridiidae } \\
\hline Coleosoma acutiventer (Keyserling, 1884) & & & & 1 & & & 1 \\
\hline \multicolumn{8}{|l|}{ Thomisidae } \\
\hline Misumenoides sp. & & & 3 & 5 & & & 8 \\
\hline Misumenops pallidus (Keyserling, 1880) & & 1 & 2 & & & & 3 \\
\hline Misumenops sp. & & 1 & & & & & 1 \\
\hline Adult abundance & 44 & 137 & 89 & 230 & 25 & 49 & 574 \\
\hline Overall abundance & 161 & 526 & 346 & 578 & 133 & 217 & \\
\hline
\end{tabular}


Table II. Multivariate GLM results and tests for between-subject effects for spider variables (abundance and species richness) considering three factors: treatment (with and without insecticide), areas (three sites in Rio Grande do Sul, Brazil) and time in days after insecticide application (DAl), and their interactions. Years are included as blocks (not shown). See text for details.

\begin{tabular}{lcccrc}
\hline \multicolumn{1}{c}{ Factor } & $\mathrm{F}$ & $\mathrm{p}$ & $\begin{array}{c}\text { Dependent } \\
\text { variable }\end{array}$ & $\mathrm{F}$ & $\mathrm{p}$ \\
\hline Area & 5.51 & $<0.001$ & $\mathrm{~S}$ & 7.07 & $<0.001$ \\
& & & $\mathrm{~N}$ & 10.89 & $<0.001$ \\
Treatment & 10.24 & $<0.001$ & $\mathrm{~S}$ & 4.30 & 0.040 \\
& & & $\mathrm{~N}$ & 20.24 & $<0.001$ \\
DAI & 15.29 & $<0.001$ & $\mathrm{~S}$ & 36.43 & $<0.001$ \\
& & & $\mathrm{~N}$ & 6.89 & $<0.001$ \\
Area * DAl & 4.28 & $<0.001$ & $\mathrm{~S}$ & 6.14 & $<0.001$ \\
& & & $\mathrm{~N}$ & 3.52 & 0.003 \\
Treatment * DAI & 0.69 & 0.654 & $\mathrm{~S}$ & 0.08 & 0.971 \\
& & & $\mathrm{~N}$ & 0.86 & 0.464 \\
Area * Treatment & 2.83 & 0.025 & $\mathrm{~S}$ & 3.63 & 0.029 \\
& & & $\mathrm{~N}$ & 2.59 & 0.058 \\
Area * Treatment * DAl & 1.05 & 0.402 & $\mathrm{~S}$ & 0.60 & 0.728 \\
& & & $\mathrm{~N}$ & 1.31 & 0.252 \\
\hline
\end{tabular}

\section{Spider family and species composition}

In rice areas without insecticide application all 12 families were found to occur, with Miturgidae and Pholcidae exclusive to this treatment. In areas with insecticide application, only the remaining 10 families were found. There were 11 families for CC and ES but 10 in CP. The ANOSIM reveals no difference between treatments $(R=0.296, p=0.196)$ or among areas $(\mathrm{R}=0.5, \mathrm{p}=0.477)$ in familial composition using the Morisita Index. Using Simpson would be inappropriate for almost all families occurred in both situations.

Among spider families Araneidae $(\mathrm{n}=877)$ was the most abundant, followed by Tetragnathidae (442), Anyphaenidae (256), Linyphiidae (122) and Lycosidae (111). Corinnidae ( $\mathrm{n}=4)$ and Pholcidae (1) were represented solely by juveniles. Of the families with more than $5 \%$ of the total abundance, the three most abundant (Araneidae, Tetragnathidae, and Anyphaenidae), were recorded more in control rice, and the other two (Linyphiidae and Lycosidae) in rice with insecticide, although not significantly as reported above (Fig. 5).

Eighteen species were shared between treatments; 8 were exclusive to rice fields with insecticide and 11 were exclusive to control rice fields. The ANOSIM tests did not indicate any differences in species composition, for either Similarity Index, between treatments (Simpson, $\mathrm{R}=0.33, \mathrm{p}=0.22$; Morisita, $\mathrm{R}=$ 0.331, $\mathrm{p}=0.29$ ), or among areas (Simpson, $\mathrm{R}=-0.05, \mathrm{p}=0.53$; Morisita, $\mathrm{R}=0.1, \mathrm{p}=0.34$ ).

The richest families in terms of species were Linyphiidae ( $\mathrm{S}=10$ ), Araneidae (6) and Anyphaenidae (5) (Table I). Among adult spiders $A$. veniliae predominated, with Tetragnatha aff. jaculator and Tetragnatha nitens (Audouin, 1826) also impor- tant, and Oxyopes salticus Hentz, 1845 also present (Table I). Ten species only occurred once ( $27 \%$ of all species).

\section{Spider feeding guilds}

Weaving spiders were more abundant (73.9\%) than hunters $(26.1 \%)$ overall, although the treatment had a strong effect (Fig. 6). Guild abundance varied between treatments, among areas, and with days after insecticide application. The insecticide treatment influenced only weaving spiders (SWB and ORB guilds, especially the latter, Table III) and not hunters (CUR and AMB guilds). The areas did not differ for running hunter spider numbers, but did so for the other three guilds. All guilds

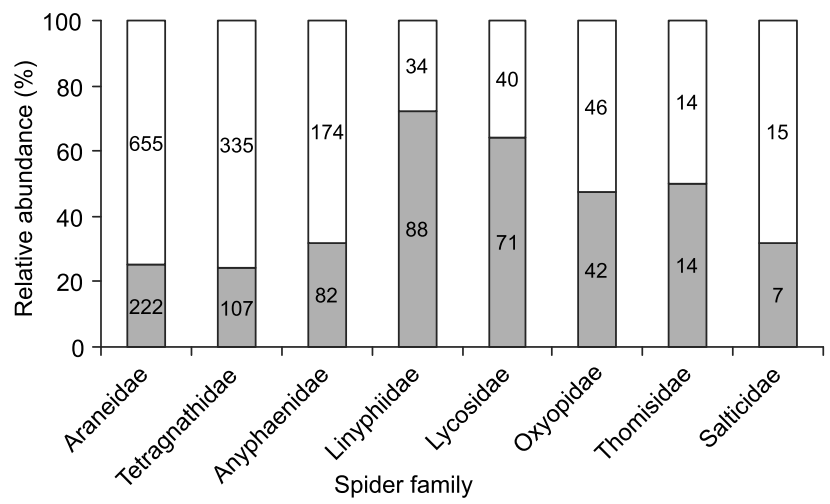

Figure 5. Effect of insecticide treatment on spider family abundances (adults and juveniles) in ricefields at Capivari do Sul, Eldorado do Sul and Cachoeira do Sul, Rio Grande do Sul, Brazil. Families in decreasing order of abundance, numbers inside columns represent absolute values. Only families with more than 20 individuals shown. ( $\square$ ) Control, ( $\square$ ) insecticide.

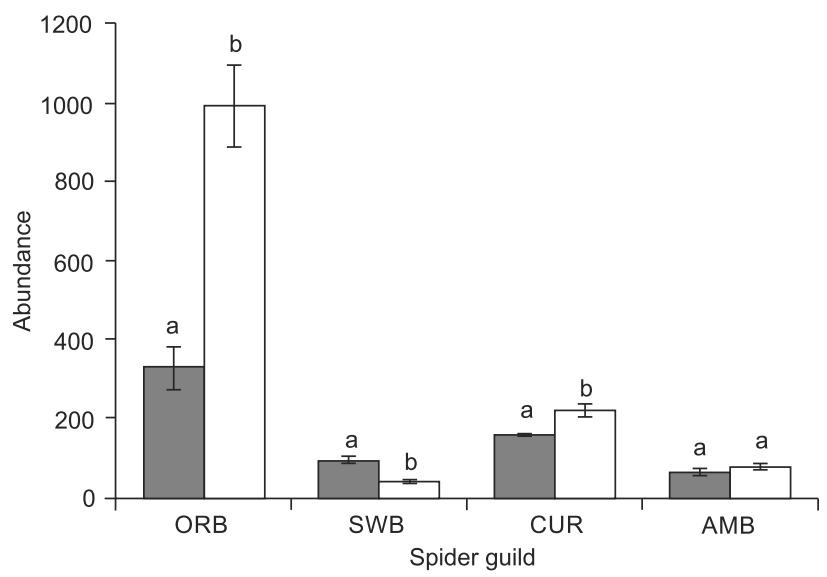

Figure 6. Spider abundance (adults and juveniles) for each of four feeding guilds in rice fields with and without insecticide (CUR, cursorial hunters; AMB, ambushing hunters; ORB, orbicular web builders; SWB, sheet web builders) (letters indicate significant differences, $p<0.05)$. ( $\square$ ) Control, ( $\square$ ) insecticide. 
Table III. Multivariate GLM results and tests for between-subject effects for spider guild abundance considering three factors: treatment (with and without insecticide), areas (three sites in Rio Grande do Sul, Brazil) and time in days after insecticide application(DAI), and their interactions. Years are included as blocks (not shown). See text for details.

\begin{tabular}{|c|c|c|c|c|c|}
\hline Factor & $\mathrm{F}$ & p & Guild & $\mathrm{F}$ & $\mathrm{p}$ \\
\hline \multirow{4}{*}{ Treatment } & 11.10 & $<0.001$ & ORB & 29.49 & $<0.001$ \\
\hline & & & SWB & 18.69 & $<0.001$ \\
\hline & & & CUR & 2.61 & 0.108 \\
\hline & & & AMB & 0.68 & 0.411 \\
\hline \multirow[t]{4}{*}{ Area } & 10.38 & $<0.001$ & ORB & 13.34 & $<0.001$ \\
\hline & & & SWB & 8.16 & $<0.001$ \\
\hline & & & CUR & 2.11 & 0.124 \\
\hline & & & $\mathrm{AMB}$ & 11.95 & $<0.001$ \\
\hline \multirow[t]{4}{*}{ DAl } & 12.33 & $<0.001$ & ORB & 1.89 & 0.133 \\
\hline & & & SWB & 70.82 & $<0.001$ \\
\hline & & & CUR & 9.25 & $<0.001$ \\
\hline & & & $\mathrm{AMB}$ & 7.96 & $<0.001$ \\
\hline \multirow[t]{4}{*}{ Area * DAI } & 2.94 & $<0.001$ & ORB & 2.88 & 0.011 \\
\hline & & & SWB & 6.77 & $<0.001$ \\
\hline & & & CUR & 2.67 & 0.017 \\
\hline & & & $\mathrm{AMB}$ & 2.29 & 0.037 \\
\hline \multirow[t]{4}{*}{ Area * Treatment } & 1.62 & 0.115 & ORB & 2.95 & 0.055 \\
\hline & & & SWB & 1.19 & 0.306 \\
\hline & & & CUR & 1.56 & 0.212 \\
\hline & & & $\mathrm{AMB}$ & 0.05 & 0.945 \\
\hline \multirow[t]{4}{*}{ DAl * Treatment } & 5.16 & $<0.001$ & ORB & 1.12 & 0.341 \\
\hline & & & SWB & 17.07 & $<0.001$ \\
\hline & & & CUR & 4.06 & 0.008 \\
\hline & & & AMB & 1.12 & 0.342 \\
\hline \multirow[t]{4}{*}{ Area * DAl * Treatment } & 1.54 & 0.046 & ORB & 0.99 & 0.431 \\
\hline & & & SWB & 0.59 & 0.737 \\
\hline & & & CUR & 2.74 & 0.014 \\
\hline & & & $\mathrm{AMB}$ & 1.06 & 0.386 \\
\hline
\end{tabular}

were affected by the time after insecticide application, indicating recovery, except ORB, which did not recover during the time sampling occurred. As area had significant interactions with DAI for all guilds, it seems that recovery of the spider fauna was dependent on the specific site. Treatment however was effective irrespective of area, although it interacted with DAI for two guilds, that is, SWB and CUR which changed differently between the two treatments in abundance with time after insecticide application as expected. AMB and ORB did not follow this pattern, the latter perhaps due to the strong negative response to the insecticide treatment.

\section{DISCUSSION}

Insecticides have a marked negative effect on overall spider abundance, as shown herein. According to RIECHERT \& LOCKLEY (1984) and РекÁr (2012) insecticide application is responsible for high mortality rates in spider assemblages in all kinds of agroecosystems. BANDARADENIYA \& EdiRISINGHE (2001), in Sri Lanka, over five consecutive rice culture cycles (1995-1998), found significant drops in spider numbers after insecticide application in every cycle. In studies conducted in India, insecticide applications on rice have consistently reported reduced spider numbers (Bora et al. 2004, Vardhani \& Rao 2002, Kumar \& Velusamy 1996). Spider species richness was also shown to strongly decrease with insecticide treatment in our study, a pattern already shown by LeE et al. (1993) for rice in South Korea.

TANAKA et al. (2000) in evaluating the toxicity of nine insecticides on predators of rice pests in Japan found that some products were very toxic to spiders, with a variation in response among spider species. In the TANAKA et al. (2000) study, the insecticide most toxic to spiders caused a resurgence of the rice planthoppers. Given our results of differing abundance and richness, combined with similar species composition, among treatments, the whole spider assemblage seems to be indiscriminately affected. However, this result is best interpreted as a smooth gradient of response to insecticide on the part of spider species; that is, there is one specific case of a positive response to insecticide $(O$. salticus: 15 individuals in insecticide areas, nine individuals in the absence of insecticide). There are a few cases of nearly complete spider species extinction in insecticide treated plots (e.g. T. nitens: two individuals in insecticide treatment, 59 individuals in the absence of insecticide). Bell et al. (2002) found a similar pattern: spider abundance reduction after herbicide application, but no change in spider species composition.

A larger number of spider families was recorded in our study than in other rice surveys conducted in southern Brazil (Corseuil et al. 1994, Rodrigues et al. 2009, Fritz et al. 2011). Also, families ranked differently in terms of abundance according to region. This highlights the differences in rice spider fauna across space - as also expressed in the significance of area as a factor in almost all comparisons employed herein. Overall species richness, even sampling from three distinct localities, was smaller than that found by Rodrigues et al. (2009) in a single area with similar sampling intensities.

Among the most abundant species collected $A$. veniliae is the most prominent, being commonly found in rice as reported from Brazil and Colombia, where it occurs on all phases of rice development, and is believed to play an important role in the control of phytophagous insects (Corseuil et al. 1994, SAAVEdra et al. 2007, Rodrigues et al. 2009). This species was also strongly affected by the insecticide in our study where the population decreased by more than $80 \%$ in insecticide treated plots as compared to unsprayed plots. Oxyopes salticus was also previously reported from rice in the State of Rio Grande do Sul (Corseuil et al. 1994, Rodrigues et al. 2009) and from natural areas adjacent to rice fields (Rodrigues et al. 2009). According to Young \& Lockley (1985) O. salticus is an ideal predator for pest population control, being more tolerant to insecticides than the pests. As mentioned above, this species was more 
abundant in rice with insecticide than without. In our study the reverse happened to Tetragnatha spiders which are also common and in rice fields (Corseuil et al. 1994, Kumar \& Velusamy 1996, TanaKa et al. 2000, Bandaradeniya \& Edirisinghe 2001, Rodrigues et al. 2009). In India, KaTti et al. (2001) verified that in areas without insecticide treatments, Tetragnatha species were abundant while few of these spiders could be found in areas treated with insecticides.

Previous work on spider guilds in insecticide-treated rice revealed that web weavers were often negatively affected: LeE et al. (1993) recorded higher numbers of hunters than web weavers after insecticide application in South Korea; HAUGHTON et al. (1999) found stronger effects on weavers both after insecticide and herbicide application in the UK. Although we have also been able to show that weavers decrease more than hunters, in our case dividing this guild in two reveals a stonger insecticide effect specifically on orbicular web builders (mainly represented by Araneidae and Tetragnathidae). A strong negative response by web weavers to insecticide is expected: both spiders and webs can be contaminated with the insecticide as the webs are more exposed, to increase the likelihood of capturing prey. On the other hand, hunters are much more mobile, being able to recolonise sprayed areas faster. However, space web builders reveal a lower impact of the insecticide than orbicular web builders, actually being more abundant in rice with insecticide. Linyphiidae spiders contributed more for this guild in rice with insecticide application. The most probable explanation is that spiders in this family show high dispersal rates due to ballooning (THомAs \& JEPSON 1999). Thus, linyphiids can also recolonise insecticide sprayed fields, faster than orb weavers, as do hunters.

RODRIGUEs et al. (2009) observed that from the early rice growth phase to the harvest period both spider abundance and species richness increase, with a sharp decrease after harvest. This trend is also seen in the data presented herein; thus, changes in spider abundance in the non-sprayed areas can be due to rice plant growth, and also to weather changes. Possibly, with insecticides being applied at intermediate phases of the rice culture, the build up in spiders would be halted. Although spider recolonisation occurs after that, as reported here, it is unclear whether rice pests would recover/recolonise faster than spiders, eliminating their natural control over such pests. DiDONET et al. (2001) stated that spiders occur usually 41 days after rice plant emergence, and up to the end of the cycle, with peaks for 48 and 52 days.

By changing the natural landscape and transforming it into a heavily managed agroecosystem, an irreparable loss in diversity ensues (Perfecto et al. 1997, Uetz et al. 1999). However, this damage is even greater when chemical products such as insecticides are also applied. The spider fauna in all the rice growing regions of the State of Rio Grande do Sul is still not well known. Many ecological processes occurring in these systems remain tentatively understood, including natural con- trol of pests. Patterns related to these processes such as spider assemblage/guild organization, behavioural interactions with the environment and fauna and spider species biology are open areas for research. As spiders are important biological control agents for regulating rice pest populations, the indiscriminate use of insecticides in such plantations is unwarranted.

Thus, to avoid the negative effect of agrochemical substances on faunal diversity in the rice culture, we urge for at least a minimization in the use of these products, and in cases where their use is considered essential, at least for the correct use and dosage. Introducing integrated pest management which includes the use of selective insecticides which control the pest but are safe to predators is the best solution. Conserving arthropod natural enemies such as spiders and other forms of biological control can, result in an increase in rice productivity and lower environmental impact (SAAVEDRA et al. 2007, FriTZ et al. 2011).

Suggestions for future studies could include longer periods for agroecosystems and insecticides, but also using varied methods so as to cover a wider portion of the fauna present and the effects of agrochemicals.

\section{ACKNOWLEDGEMENTS}

Erica H. Buckup, Maria A. de L. Marques and Ricardo Ott for access to MCN spider material and bibliography. We are grateful to anonymous reviewers and editors for important suggestions.

\section{LITERATURE CITED}

Ambalagan, G. \& P. Narayanasamy. 1999. Population fluctuation of spiders in the rice ecosystem of Tamil Nadu. Entomol 24: 91-95.

BandaradenIYA, C.N.B. \& J.P. EdIRISINGHE. 2001. The ecological role of spiders in the rice fields of Sri Lanka. Biodiversity 2: 3-10.

Bell, J.R.; A.J. Haughton; N.D. Boatman \& A. Wilcox. 2002. Do incremental increase of the herbicide glyphosate have indirect consequences for spider communities? Journal of Arachnology 30: 288-297.

Bora, D.K.; U. Bhuyan; G. Katti \& I.C. Pasalu. 2004. Quantification of insect pest and natural enemy incidence vis a vis yield. Uttar Pradesh Journal of Zoology 24: 187-190.

Corseuil, E.; M.C.Z. Paula \& A.D. Brescovit. 1994. Aranhas associadas a uma lavoura de arroz irrigado no município de Itaqui, Rio Grande do Sul. Biociências 2: 49-56.

Clarke K.R. \& R.M. Warwick. 1994. Change in Marine Communities. National Research Concil.

Croft, B.A. 1990. Arthropod Biological Control Agents and Pesticides. New York, Wiley and Sons.

Desneux, N.; A. Decourtye \& J.M. Delpuech. 2007. The sublethal effects of pesticides on beneficial arthropods. Annual Review of Entomology 52: 81-106 
Dias, S.C.; L.S. Carvalho; A.B. Bonaldo \& A.D. Brescovit. 2010. Refining the establishment of guilds in Neotropical spiders (Arachnida, Araneae). Journal of Natural History 44: 219-239.

Didonet, J.; A.P.P. Didonet; E.L. Erasmo \& G.R. Santos. 2001. Incidência e densidade populacional de pragas e inimigos naturais em arroz de terras altas, em Gurupi, TO. Bioscience Journal 17: 67-76.

Fritz, L.L.; E.A. Heinrichs; V. Machado; T.F. Andreis; M. Pandolfo; S.M. Salles; J.V. Oliveira \& L.M. Fiuza. 2011. Diversity and abundance of arthropods in subtropical rice growing areas in the Brazilian south. Biodiversity and Conservation 20 (10): 2211-2224.

Hammer, O \& D.A.T. Harper. 2009. Past: Paleontological Statistics. Version 1.97. Available online at:http:// folk.uio.no/ohammer/past [Accessed: 16/V/2013]

Haughton A.J.; J.R. Bell; N.D. Boatman \& A. Wilcox. 1999. The effects of different rates of the herbicide glyphosate on spiders in arable field margins. Journal of Arachnology 27: 249-254.

Haughton, A.J.; J.R. Bell; N.D. Boatman \& A. Wilcox. 2001. The effect of herbicide glyphosate on non-target spiders. II. Indirect effects on Lepthyphantes tenuis in field margins. Pest Management Science 57: 1037-1042.

Katti G.; I.C. Pasalu; N.R.G. Varma \& N. Dhandapani. 2001. Quantification of natural biological control in rice ecosystem for possible exploitation in rice IPM. Indian Journal of Entomology 63: 439-448.

Kumar, M.G. \& R. Velusamy. 1996. Safety of insecticides to spiders in rice fields. Madras Agriculture Journal 83: 371-375.

LEE, H.P.; J.P. KIM \& J.R. Jun. 1993. Utilization of insect natural enemies and spiders for the biological control in rice paddy filed, community structure of insect pest and spiders, suppress effect on insect pest by natural enemies, and their overwintering habitats in rice paddy field. Journal of Agriculture Science 35: 261-274.

LeE, J.H. \& S.T. Kim. 2001. Use of spiders as natural enemies to control rice pest in Korea. Available from: http:// www.agnet.org/library/article/eb501.html\#eb501f1 [Accessed: 10/VI/2013]

Murata, K. \& K. Tanaka. 2004. Spatial interaction between spiders and prey insects: horizontal and vertical distribution in a paddy field. Acta Arachnologica 53: 5-86.
PeKÁR, S. 2012. Spiders (Araneae) in the pesticide world: an ecotoxicological Review. Pest Management Science 68: 1438-1446.

Perfecto, I; J. Vandermeer; P. Hanson \& V. Cartian. 1997. Arthropod biodiversity loss and the transformations of a tropical agroecosystem. Biodiversity and Conservation 6: 935-945.

Ponce, C.; C. Bravo; D.G. León; M. Magaña \& J.C. Alonso. 2011. Effects of organic farming on plant and arthropod communities: A case study in Mediterranean dryland cereal. Agriculture, Ecosystems \& Environment 141: 193-201.

RodRigues, E.N.L.; M.S. MENDONÇA JR. \& R. OTT. 2009. Spider diversity in a rice agroecosystem and adjacent areas in southern Brazil. Revista Colombiana de Entomología 35: 78-86.

Riechert, S.E. \& T. Lockley. 1984. Spiders as biological control agents. Annual Review of Entomology 29: 299-320.

SaAvedra, E.C.; E.D. Flórez \& C.H. Fernández. 2007. Capacidad de depredación y comportamiento de Alpaida veniliae (Araneae: Araneidae) en el cultivo de arroz. Revista Colombiana de Entomología 33: 74-76.

SigSGAARD, L. 2000. Early season natural biological control of insect pests in rice by spiders - and some factors in the management of the cropping system that may affect this control, p.57-64. In: S. Toft \& N. ScharfF (Eds). European Arachnology. Aarhus, Aarhus University Press.

Tahir, H.M.; A. Butt \& S.M. Sherawat. 2009. Foraging strategies and diet composition of two orb web spiders in rice ecosystems. Journal of Arachnology 37: 357-362.

TanaKa, K.; S. Endo \& H. Kazano. 2000. Toxicity of insecticides to predators of rice planthoppers: spiders, the mirid bug and the drynid wasp. Applied Entomology and Zoology 35: 177-187.

Thomas, C.F.G. \& P.C. Jepson. 1999. Differential aerial dispersal of linyphiid spiders from a Grass and a cereal field. Journal of Arachnology 27: 294-300.

UetZ, G.W.; J. Halaj \& A.B. Cady. 1999. Guild structure of spiders in major grops. Journal of Arachnology 27: 270-280.

VARDHANI, B.P. \& K.T. RAO. 2002. Effect of normal and sub-normal application of insecticides on brown planthopper and its predators. Journal of Applied Zoological Researches 13: 74-75.

Young, O.P. \& T.C. LockLeY. 1985. The striped lynx spider, Oxyopes salticus (Araneae: Oxyopidae), in agroecosystems. Entomophaga 30: 329-346.

Submitted: 13.VI.2013; Accepted: 09.IX.2013.

Editorial responsibility: Antonio D. Brescovit 